\title{
Impacts of climate warming on forests in Ontario: Options for adaptation and mitigation
}

\author{
by C.S. Papadopol ${ }^{1}$
}

\begin{abstract}
This paper summarizes current knowledge about the optical properties of greenhouse gases and general climate-warming influences. It explains the influence of this new phenomenon on the major ecosystems of the world, and considers the process of deforestation. It then analyzes the warming trends in Ontario based on data from two weather stations with continuous records of more than 120 years, to determine the rate of warming in the Great Lakes-St. Lawrence Region. The results indicate a temperature increase of about $0.76^{\circ} \mathrm{C}$ per century and an $8 \%$ increase in annual total precipitation.

Current climate change models indicate that for a scenario of $2 \times \mathrm{CO}_{2}$ levels some general, probable prognoses can be made, including a temperature increase of up to $4.5^{\circ} \mathrm{C}$, which might be disastrous for existing forest ecosystems. Specifically, the consequences of climate warming on (a) northward shifts of ecological conditions, (b) forest productivity, and (c) forest physiology and health, are examined. In the context of global warming, the paper then recommends practical management measures necessary to ensure adaptation of existing forest ecosystems to the warming that is already developing. These measures are intended to provide a no-risk environment for existing forests until rotation age. Next, a wide range of mitigative measures is examined with a view to securing the longterm preservation of forest ecosystems to avoid major ecological disruptions and, gradually, to reverse climate warming. Application of these measures requires international consensus, but countries that apply these recommendations first have a chance to profit from them due to the " $\mathrm{CO}_{2}$ fertilization" effect.
\end{abstract}

Key words: climate change, silviculture, forest management

Cet exposé résume les connaissances actuelles sur les propriétés optiques des gaz à effet de serres et sur les conséquences générales du réchauffement climatique. Il explique l'influence de ce nouveau phénomène sur les principaux écosystèmes mondiaux, et s'attarde au processus de déboisement. Il analyse par la suite les tendances au réchauffement en Ontario, selon les données de deux stations météorologiques pour lesquelles nous avons des relevés continus pour plus de 120 ans, afin de déterminer le taux de réchauffement dans la région des Grands-Lac-St-Laurent. Les résultats indiquent une augmentation de la température de l'ordre de $0,76^{\circ} \mathrm{C}$ par siècle et une augmentation de $8 \%$ des précipitations annuelles totales.

Les modèles actuels de changement climatique indiquent que, pour un scénario de doublement des niveaux de $\mathrm{CO}_{2}$, des pronostics généraux et probables peuvent être établis, dont une augmentation de la température pouvant atteindre $4,5^{\circ} \mathrm{C}$, ce qui serait désastreux pour les écosystèmes forestiers existants. Les conséquences du réchauffement climatique soit a) le déplacement vers le nord des conditions écologiques, b) la productivité forestière, et c) la physiologie et la santé des arbres sont étudiées plus attentivement. Dans le contexte de réchauffement mondial, cet exposé recommande des mesures d'aménagement pratiques nécessaires pour assurer une adaptation des écosystèmes forestiers actuels au réchauffement qui est déjà en train de se produire. Ces mesures visent à procurer un environnement sans risque pour les forêts actuelles jusqu'en fin de révolution. Par la suite, une grande variété de mesures de mitigation est étudiée sous l'optique de maintenir la préservation à long terme des écosystèmes forestiers afin d'éviter de graves ruptures écologiques, et graduellement, pour faire reculer le réchauffement climatique. La mise en place des ces mesures nécessite un consensus international, mais les pays qui appliqueront ces recommandations dès maintenant auront la chance d'en retirer des profits grâce à l'effet de fertilisation par le $\mathrm{CO}_{2}$.

Mots-clés: changement climatique, sylviculture, aménagement forestier

\section{Introduction}

Over the last 200 years, the Earth's atmosphere has been accumulating heat in a slow, continuous way, imperceptible to humans but with significant consequences for the planet, through a physical process triggered, especially, by the optical properties of carbon dioxide gas (Harrington 1987, Mudge 1997). When the gaseous mixture of a clean atmosphere is traversed by shortwave incoming radiation there is no energy absorption. Conversely, when thermal, infrared, or long-wave radiation returns to space, some of the gases that form the atmosphere appear opaque to the long-wave radiation and generate heat in proportion to their concentration and opaqueness (Bolin et al. 1986, Leggett 1990). Thus, slowly, over the last 200 years, coincidental with the industrial revolution when humans started the large-scale use of fossil fuels, roughly concurrent with aggres-

${ }^{1}$ Ontario Ministry of Natural Resources, Ontario Forest Research Institute, 1235 Queen Street East, Sault Ste. Marie, Ontario P6A 2E5. sive deforestation (Leggett $e t$ al. 1992, Adger and Brown 1994), the concentration of $\mathrm{CO}_{2}$ increased and its effect became manifest. These changes have influenced many processes now felt at various scales around the globe: increasing climatic variability resulting in severe droughts and floods, advancing desertification, melting glaciers and permafrost and rising oceans levels. At the same

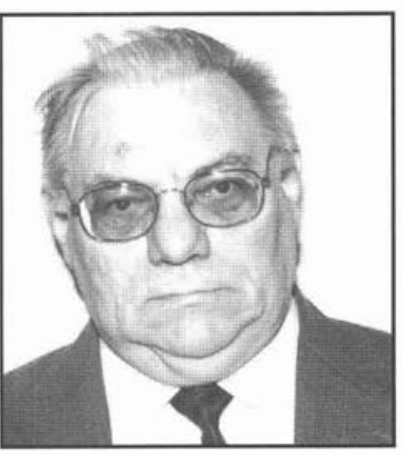

C.S. Papadopol time, especially in the last few decades, the frequency of extreme phenomena (severe floods, prolonged droughts, extensive fires, etc.) has increased (Houghton 1997).

The mechanism through which the average temperature of the earth's surface, currently around $15^{\circ} \mathrm{C}$, is kept relatively 
constant appears to have been upset. The gases with special optical properties that are responsible for this effect include carbon dioxide $\left(\mathrm{CO}_{2}\right)$, water vapour $\left(\mathrm{H}_{2} \mathrm{O}\right)$, methane $\left(\mathrm{CH}_{4}\right)$, nitrous oxide $\left(\mathrm{N}_{2} \mathrm{O}\right)$, nitrogen oxides $\left(\mathrm{NO}_{\mathrm{x}}\right)$, stratospheric ozone $\left(\mathrm{O}_{3}\right)$, carbon monoxide $(\mathrm{CO})$, and chlorofluorocarbons (CFC). These are known as greenhouse gases (GHGs). In general terms, the addition of particulate matters to this mixture over the last century has increased the opacity of the atmosphere even more. Thus, year after year, heat remains trapped in the troposphere, warming the planet, with potential far-reaching consequences to life (Bolin et al. 1986). Compared to the age of the Earth, this phenomenon is recent, a consequence of the industrial revolution and the development of fuel-powered transportation, which both require enormous quantities of energy obtained mostly through burning fossil fuels. While these are the sources of the additional $\mathrm{CO}_{2}$, which was previously stored underground and is now floating into the atmosphere, massive deforestation (Adger and Brown 1994) to allow agricultural development, has diminished the natural sinks of $\mathrm{CO}_{2}$ and has activated decomposition of organic matter stored in soil. Today, most of the scientific community accepts this explanation of the warming of atmosphere (Bolin et al. 1986). At a basic level, both the increased $\mathrm{CO}_{2}$ emissions and the reduced carbon density in many forest ecosystems are seen as a direct consequence of the explosion in the world population over the last two centuries (Houghton 1997, Gjerstad and South 1999).

Continuation of this situation may lead to a series of uncontrollable effects, considered serious by various international organizations, especially by the Intergovernmental Panel on Climate Change (IPCC) (Leggett et al. 1992). Under the auspices of the United Nations, this organization started a vigorous brainstorming program and is planning far-reaching measures to stop and reverse the warming trend. Along with conserving fossil fuels by limiting their use, improving forest management is increasingly seen as an important means to reverse this trend, since forests can play an important role in the carbon budget of ecosystems (Watson et al. 1996).

The objectives of this paper are to (a) briefly examine the causes of climate warming, (b) investigate the consequences of warming on forest ecosystems, (c) determine the means to adapt existing forests to this challenge, and (d) recommend longterm action to mitigate warming through increasing forest sequestration of carbon.

\section{The Agents of Change}

Water vapour, the most abundant gas in the atmosphere, is either transparent (atmospheric moisture) or opaque to incoming short-wave radiation (clouds). At the same time, it is opaque to outgoing long-wave, thermal radiation. Due to the shifting role of water in the heat balance of the atmosphere, both between seasons and in the diurnal cycle, the effects of water vapour are the most difficult to quantify and simulate (Harries 1996). After water, carbon dioxide is the most abundant optically active gas. It is released into the atmosphere through burning (fossil fuels and firewood) and the thermally controlled, slow process of organic matter decomposition. Large sources of methane are released through either anaerobic plant decomposition in various biological systems (rice paddies, swamps and bogs) or as a by-product of digestive systems dependent on enteric fermentation (cattle, other livestock and termites). Nitrous oxide is emitted as a result of incomplete use of nitrogenous fertilizers and fossil fuel ignition. Uncertainties still exist with respect to $\mathrm{N}_{2} \mathrm{O}$ fluxes and their rates in various ecosystems. Carbon monoxide results from slow, incomplete burning of biomass. It is not an optically active gas, but it can influence the ability of the atmosphere to control oxidation. Finally, chlorofluorocarbons come from industrial, anthropogenic sources. Although present as only a minute proportion of the atmosphere, one molecule of these compounds has a warming effect 5 to 10 thousand times greater than a molecule of $\mathrm{CO}_{2}$.

Greenhouse gases are produced by natural phenomena and human actions. For millennia, the natural emissions of these optically active gases were relatively in balance with the sinks, maintaining a steady $\mathrm{CO}_{2}$ concentration of atmosphere through photosynthesis. However, over the last 200 years, anthropogenic activities began to upset this $\mathrm{CO}_{2}$ balance, resulting in significantly increased $\mathrm{CO}_{2}$ concentrations and leading to perceptible climate warming. Today, the most important sources of $\mathrm{CO}_{2}$ remain burning of fossil fuels in industry (coal and oil), domestic heating (coal, oil and wood), transportation (oil and coal), and deforestation (burning and soil exposure). In 1988, an estimated 6 gigatonnes, $\mathrm{Gt},(1 \mathrm{Gt}=1$ gigatonne $=1000$ million tonnes) of $\mathrm{CO}_{2}$ was released into the atmosphere from anthropogenic sources (Andrasko 1990), but newer data place this amount at $8 \mathrm{Gt}$ (Houghton 1997). Industrialized countries contributed about $75 \%$ of this release. As a result, since the beginning of the industrial era, the amount of $\mathrm{CO}_{2}$ in the atmosphere has increased by about 25\% (Andrasko 1990).

Researchers have been aware of the effects of increased $\mathrm{CO}_{2}$ content in the atmosphere for more than 100 years, (Mudge 1997). Especially during the past two to three decades, evidence has indicated that the increasing emissions may change the earth's radiative balance, resulting in a gradual, long-term increase of the atmosphere's average temperature (Karl et al. 1996).

\section{The Warming Potential of Gases}

The individual components of this highly variable mixture of gases have - to different degrees - two important characteristics, namely: (a) an average residence time in the atmosphere, and (b) a characteristic radiative forcing. The concept of global warming potential (GWC), which combines these two traits, has emerged from the deliberations of the IPCC (Bolin et al. 1986, Houghton 1997). Table 1, presents estimates of annual emissions of GHGs and their contribution to greenhouse forcing in the $1980 \mathrm{~s}$, stressing the consequences of tropical deforestation, which is responsible for about $25-33 \%$ of current $\mathrm{CO}_{2}$ emissions, $35 \%$ of $\mathrm{CH}_{4}$, and probably $25-30 \%$ of $\mathrm{N}_{2} \mathrm{O}$ (Andrasko 1990, Isaksen 1992).

\section{Typical Emissions of Various Forest Ecosystems}

All ecosystems continuously emit and sequester $\mathrm{CO}_{2}$, with the forest storing 20 to 100 times more carbon (C) per unit area than agricultural crops (Ehleringer and Bjorkman 1977). Since a much lower proportion of forest biomass is readily decomposed, forests are clearly more effective than agricultural crops in maintaining the equilibrium between release and sequestration of carbon. Nevertheless, some uncertainty still exists relative to carbon storage in forest cover and particularly the emissions resulting from changes of this cover for alternative land uses, e.g., slash-and-burn agriculture. Also, no reliable estimates exist about the $\mathrm{CO}_{2}$ releases during this century 
Table 1. Estimated global annual emissions of major greenhouse gases, relative importance in greenhouse forcing, and contribution from forest systems (adapted from Andrasko 1990, Isaksen 1992).

\begin{tabular}{lccc}
\hline Gas & Annual emission & $\begin{array}{c}\text { Radiative forcing } \\
\text { relative to } \mathrm{CO}_{2}\end{array}$ & $\begin{array}{c}\text { Contribution to } \\
\text { greenhouse effect in 1980s }\end{array}$ \\
\hline $\begin{array}{l}\text { Carbon dioxide }\left(\mathrm{CO}_{2}\right) \\
\text { Industrial/energy }\end{array}$ & 1 & $50 \%$ \\
Biotic (natural) & $5.6 \mathrm{Pg} \mathrm{C}$ & & \\
Tropical forest conversion & $0.4-2.6 \mathrm{Pg} \mathrm{C}$ & 25 \\
Methane $\left(\mathrm{CH}_{4}\right)$ & $0.4-2.6 \mathrm{Pg} \mathrm{C}$ & & $20 \%$ \\
Industrial/energy & & \\
Biotic (natural) & $50-100 \mathrm{Tg} \mathrm{C}$ & & \\
Tropical forest conversion & $20-875 \mathrm{Tg} \mathrm{C}$ & 250 & $\sim 6 \%$ \\
Nitrous oxide $\left(\mathrm{N}_{2} \mathrm{O}\right)$ & $140-320 \mathrm{Tg} \mathrm{C}$ & \\
\hline uncertain & & \\
\hline
\end{tabular}

Note: $1 \mathrm{Pg}($ pentagram $)=10^{9}$ tonnes; $1 \mathrm{Tg}($ teragram $)=10^{6}$ tonnes

from deforestation, especially about the fluxes of $\mathrm{CO}_{2}$ from soils that were previously under forest. Rough estimates show that in disturbed tropical forest ecosystems about one third of the carbon emissions originate from the soil, which, when exposed, absorbs more heat and shifts from a sink to a source (Wigley 1993).

The carbon content in biomass of the boreal forest (largely coniferous) in North America is now estimated at about 9700 million tonnes (Houghton 1997), much less than a previous estimate (Andrasko 1990).

Temperate forest. The forests of Europe and North America contributed heavily to global carbon emissions in the past when they were burnt for industrial development and domestic heating, or cleared for agricultural production. Today, the forests in this zone are in balance in terms of carbon cycling, as their annual increment is about equal to timber harvest and deforestation for urban growth and other land uses (Houghton 1997).

Tropical forest. These forests, divided into wet and dry tropics, occur mostly in Africa, Asia, and Latin America. Brown (1988) shows that in the wet tropical forest, carbon amounts to $187 \mathrm{tC} /$ per ha, $160 \mathrm{tC} /$ per ha and $155 \mathrm{tC} /$ per ha, respectively, while in the dry tropical forest, it averages only $63 \mathrm{tC} /$ per ha, $27 \mathrm{tC} /$ per ha and $27 \mathrm{tC} /$ per ha, respectively. However, the deforestation rate of these forests, which are located in over-populated areas of the globe, has risen alarmingly. Dixon et al. (1994) estimate that, in the 1990s, the annual deforestation rate in low latitudes was as great as 15.4 million ha per year, while Andrasko (1990), quoting FAO, states that the total deforestation of tropical forest amounted to about 17 million hectares annually, almost exclusively by burning.

\section{Predictions of Climate Change}

Most studies of possible climate-induced changes in forests have used standard atmospheric general circulation models (GCMs) of global climate, especially the GISS (Goddard Institute of Space Sciences) and GFDL (Geophysical Fluid Dynamics Laboratory) climatic models (Dixon et al. 1994). These highly complex three-dimensional models of atmospheric, oceanic and terrestrial interactions cover the whole globe and attempt to forecast global climate change most often under a scenario of doubled atmospheric concentrations of $\mathrm{CO}_{2}$, the so called $2 \times \mathrm{CO}_{2}$ scenario. Under this scenario, they forecast an air temperature increase of between $2.8^{\circ} \mathrm{C}$ and $5.2^{\circ} \mathrm{C}$ and an increase of precipitation between $7.1 \%$ and $15.8 \%$.
At this stage, serious uncertainties still exist in modelling feedback of GCMs, which only crudely model ocean circulation, water vapour, clouds, snow and ice coverage. Further, their spatial resolution remains poor, limiting their ability to forecast regional climate change effects. Despite these drawbacks, which may dissipate as the technology evolves, GCMs have enabled some credible climate predictions, summarized below after Houghton (1997):

- Global - mean surface warming (very probable): By the middle of this century, surface warming will likely occur in the range of between $1.5-4.5^{\circ} \mathrm{C}$, for a $2 \times \mathrm{CO}_{2}$ scenario.

- Global - mean precipitation increase (very probable): Increased heating of the Earth's surface will lead to faster recycling of water and thus greater global mean precipitation, although some regions could get less rainfall due to changing air circulation.

- Global - rise in mean sea level (very probable): This rise will result from the thermal expansion of sea water and an acceleration in the rate of melting of glaciers and polar ice caps. These predictions are among the most certain.

- Northern high latitude precipitation increase (probable): High latitudes are expected to experience increased intrusion of warm and moist air, resulting in permafrost melting and increased annual precipitation.

- Summer continental dryness/warming (probable): Models are forecasting significant reduction of soil moisture for mid-latitude continental regions in summer, resulting from earlier snow melt and reduced summer precipitation.

- Regional vegetation changes (probable): These are inevitable as the optimal vegetation areas shift north, raising concerns about the regeneration of today's major forest types. - Tropical storm increases (probable): A more active atmosphere will increase the frequency and intensity of tropical storms usually associated with a warmer and wetter climate.

Local conditions could exacerbate these general effects. For instance, where abundant snow falls, the amount of damage from avalanches and/or rapid melting and flooding could reach critical levels. Droughts will be aggravated on sandy substrates, and the moisture stresses could reach levels intolerable for any vegetation, thus increasing the extent of barren areas. Extreme temperatures will increase evapotranspiration, most likely eliminating the less drought-tolerant species in various ecosystems. Finally, the increasing temperature and dryness will greatly increase forest fire risks. 


\section{Determining Climate Warming in Ontario}

In the beginning, the warming of the atmosphere was a slow, elusive process, masked by the variability of annual temperature. However, as the patterns of air circulation change in the future, regional forecasting will gain in importance, diminishing or enhancing the general predictions presented above.

Air temperature and precipitation data files from stations with the longest records were analysed for this study. These records can presumably contribute valuable information about climate warming, provided the sites were not located in "heat islands," urban areas that grew and modified the microclimate. Port Dover (on the northern shore of Lake Erie) and Parry Sound (on Lake Huron) were selected among the few stations in Ontario that have both long records and limited surrounding development. The annual average temperatures and the annual sums of precipitation for these localities are presented in Fig. 1 and Fig. 2.

Over the last century the climate of the two localities, which roughly represent the range of variation for the Great Lakes-St. Lawrence Region of Ontario, appears to be warming continuously, consistent with data presented by Boden $e t$ al. (1994) for the same geographical region. The records show that temperature has increased on average by about $0.76^{\circ} \mathrm{C}$ in both stations this century. However, it is unclear whether the data show an exponential, rather than linear, increase towards the end of the interval. A comparison between the temperature regression lines (Fig. 1) shows that the Parry Sound line is slightly steeper than the Port Dover line. This difference might be consistent with the GCMs' prognosis for more substantial warming at higher latitudes (Karl et al. 1994), although this effect cannot be demonstrated with confidence on such geographically limited data sets. Precipitation follows a similar, somewhat less marked, evolution (Fig. 2), indicating an $8 \%$ increase in the same interval, This appears reasonable given that warming leads to increased evaporation.

\section{Potential Effects of Climate Change on Forests}

Many scientists believe that the effects of climate change will be serious, especially through their ecological consequences. They argue that the warming trend will shift favourable growing conditions north for every vegetation zone, destabilizing all ecosystems. They also fear major impacts on commercial forestry, timber supply, and recreation (Wheaton et al. 1987), ecosystem disruption (Peter 1990), or a major ecological disturbance that may make forestry non-sustainable over vast areas (Houghton 1997). Another forecast says that, in the northern hemisphere, the forest area will diminish by about 444 million ha, while boreal forests will decline by $37 \%$ in area and lose $60.4 \mathrm{Gt}$ in biomass. Tropical forests will gain $28 \%$ in area and $57.8 \mathrm{Gt}$ in biomass. Total global forests are expected to decline $14.1 \mathrm{Gt}$ in carbon density under the $2 \times \mathrm{CO}_{2}$ scenario (Sedjo and Solomon 1989). The most likely effects in such a scenario are going to be apparent in three areas, namely:

1. A shift of conditions. Due to warming, the well-established zones in which various forest species are able to regenerate naturally will no longer match the thermal requirements of these species. This will result in successional pressure for a certain species/ecosystem to move, losing territory at the southern fringe and gaining it at the northern fringe. Obviously, ecosystem stability or the health of a forest under such stress might suffer, rendering it more vulnerable to various biotic (diseases and insects) and abiotic (drought, pollution and fires) agents. Composition might change significantly during this transition, owing to variations of requirements and ability to move among the species of the same ecosystem, with a great loss of biodiversity.

According to these predictions and adapting the conclusions of Kellomaki et al. (1997), in the boreal forest of Ontario, we should expect, first of all, a positive and sizable influence on growth due to extension of the growing season, supplementary precipitation and increased $\mathrm{CO}_{2}$, although Solomon et al. (1981) believe that under a $2 \times \mathrm{CO}_{2}$ scenario, what we know now as boreal forest will no longer have boreal tree species. Altogether, the southern border of the boreal forest zone will probably move in a northward direction by $250-900 \mathrm{~km}$, while the southern limit of this zone will withdraw by only 70-700 $\mathrm{km}$, resulting in a loss of area (Wheaton et al. 1987).

A similar but less extensive move is predicted for the temperate forests. Hardwoods and savannah will likely increase.

2. Changes in forest productivity. Beginning in 20 to 50 years, productivity could drop by $40-100 \%$, especially at the southern edges of species ranges, due mostly to insufficient water availability. However, in the centre of species' ranges, for example in northeastern Ontario, productivity of black spruce could improve remarkably as long as water remains accessible. Under an enriched precipitation regime, as illustrated in Fig. 2, the boreal forest at large will benefit to a certain extent from both the warming and the growing season expansion, except on very permeable substrates. A consequence of this local, yet extended, circumstance could have economic importance over northeastern Ontario. Controlled lowering of the water table on black spruce sites, providing an aerobic medium for the root zone, could result in significant biomass growth stimulation and be a boon to the economy.

3. Changes in tree physiology and growth. The key change in this area will likely be an extended growing season. Recent European studies show that, due to warming at comparable latitudes in Europe, the growing season has already increased by 11 to 14 days, a significant change for a relatively brief growing season. Such subtle, but major, changes will have great ecological implications, including effects on tree increment and forest yield (Peter 1990, Whitehead et al. 1992). This influence is gradual and, although not proven yet in scientific literature, will likely increase slightly provided no severe water supply shortages occur. It is conceivable that this is already occurring.

More difficult to predict are changes in natural regeneration. The main species will likely move north, but changing conditions could impose a certain screening of the respective ecosystems, reducing species diversity. In addition, especially at the southern fringes of species' ranges, stand decline and tree mortality will increase due to increases in insect populations and tree diseases. Finally, the incidence of fire and abiotic damage to forests will generally be more severe, especially in stands that will suffer moisture stress because of drier and warmer summers. 

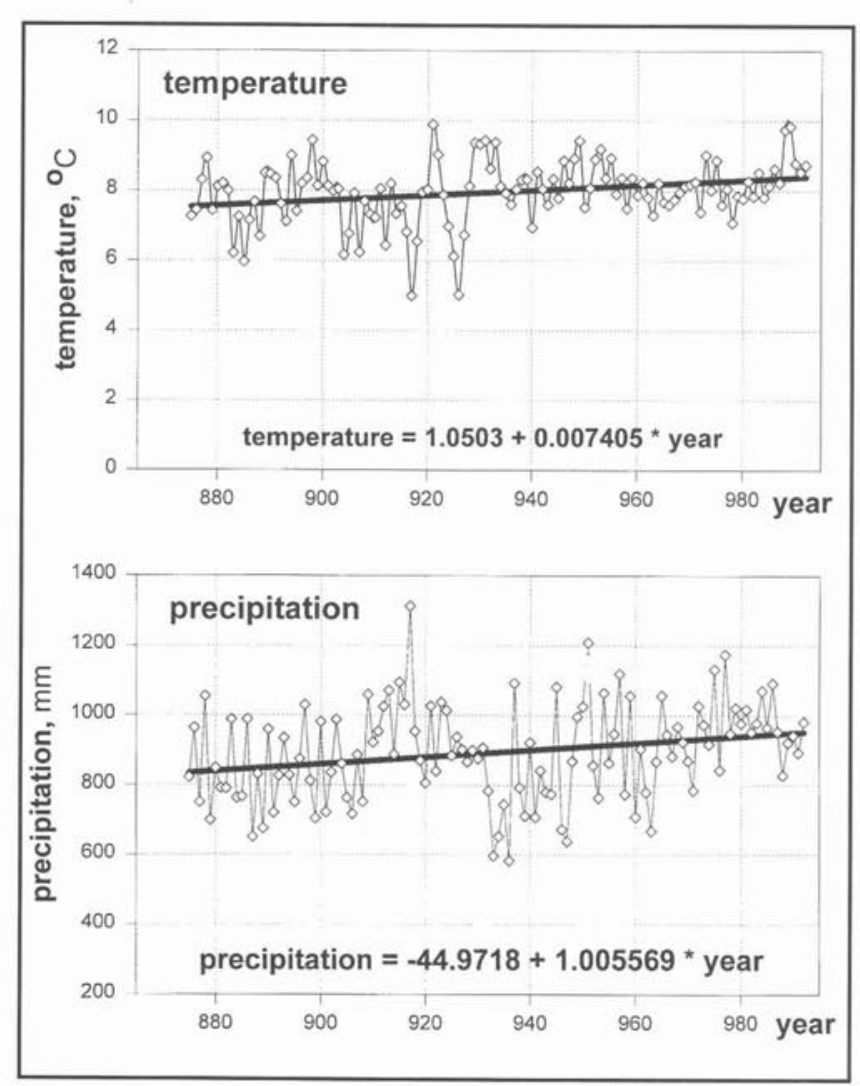

Fig. 1. Temperature and precipitation trends of Port Dover, Ontario. Source: Environment Canada.

\section{Secondary Effects}

Overwhelming experimental evidence indicates that atmospheric $\mathrm{CO}_{2}$ enrichment increases photosynthesis and biomass accumulation. To date, laboratory and field studies in opentop chambers of the effects of elevated $\mathrm{CO}_{2}$ levels on agricultural plants, especially legumes and flowers, have demonstrated the following effects: (1) increased rates of photosynthesis, (2) lower plant water-use requirements, (3) increased carbon sequestering, and (4) increased soil microbial nitrogen-fixing activity (Hardy and Havelka 1975). In forestry numerous trials with seedlings of various species grown in controlled conditions have confirmed the positive influence of a $\mathrm{CO}_{2}$-enriched atmosphere on growth and water use (Yeatman 1970, Tinus 1972, Sionit et al. 1985, Tolley et al. 1985, Kramer and Sionit 1987, Lee et al. 1993b). It is now well established that increased $\mathrm{CO}_{2}$ could benefit young trees, especially those experiencing water stress.

Quantifying the positive effect of a $\mathrm{CO}_{2}$-enriched atmosphere for mature trees probably began with LaMarche et al. (1984), who detected ring-width increases that could be explained only through increased $\mathrm{CO}_{2}$ concentrations. Also, Lee et al. (1993a) provide evidence of the same effect for Sitka spruce. However, an increase in biomass accumulation of forest communities is only now beginning. Of special importance is a Finnish study arguing that a combination of temperature increases of $0.4^{\circ} \mathrm{C}$ per decade, $10 \%$ increase in the annual sum of precipitation and increase of atmospheric $\mathrm{CO}_{2}$ content by $33 \mu$ mol per decade will increase timber yields by $30 \%$ in one rotation (Kel-
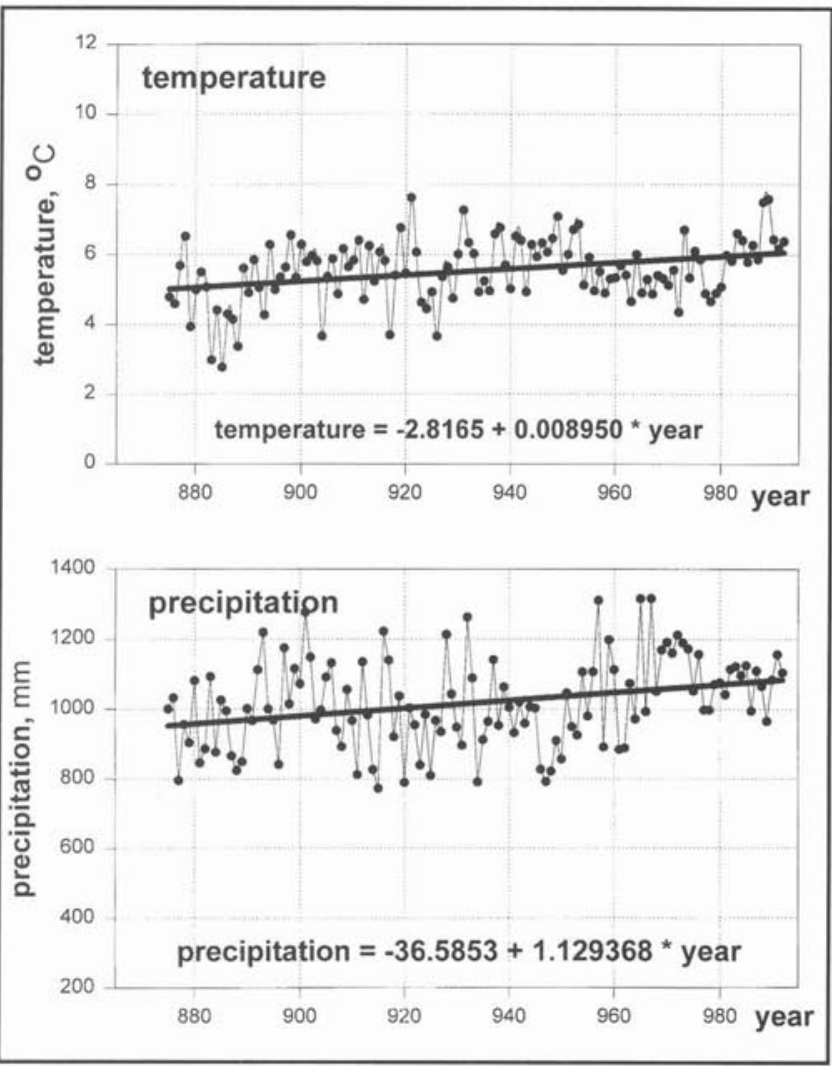

Fig. 2. Temperature and precipitation comparison, Parry Sound, Ontario. Source: Environment Canada.

lomaki et al. 1997). Research on the $\mathrm{CO}_{2}$ balance of a stand of loblolly pine (Pinus taeda L.), using a very sophisticated methodology, has recently concluded that biomass accumulation was strongly increased by augmented $\mathrm{CO}_{2}$ concentration (McLeod and Long 1999). Other such sophisticated facilities are in use in the US for other important forest species. This subject needs more research, not only for the economic interest but also to develop mitigation strategies that are based on enhancing the forests' ability to re-sequester $\mathrm{CO}_{2}$. Moreover, it is extremely important to determine which species have a high biomass production response to increased $\mathrm{CO}_{2}$, so we can promote their expansion if it is also ecologically and economically appropriate. Canada, with diverse but generally favourable climates for forestry, a large forest industry, and vast areas with poorly regenerated forests, should be very interested in such action for both environmental and economic reasons.

Perhaps the most assured prediction of climate warming is the effect on fire frequency and magnitude (Main 1987, Andrasko 1990).

Another predictable effect is the migration of insects and diseases, which have a characteristic narrow range of thermal need/tolerance. Increased heat can accelerate the breeding potential of insects, resulting in more generations per year (Hedden 1987). This phenomenon has been observed with locusts in arid zones in West and East Africa and in India, where migration patterns have been modified (Mabbutt 1987). 


\section{A Strategy to Slow and Reverse Climate Warming \\ The International Scene}

The state of the atmosphere was considered in an international context for the first time In June 1992, at the United Nations Conference on Environment and Development (UNCED) in Rio de Janeiro. UNCED issued the Framework Convention on Climate Change (FCCC), later signed by 160 countries. This convention took effect in early 1994 and put forward an agenda for slowing down climate change and stabilizing emissions of optically active gases. The convention acknowledged the profound ecological effects of climate warming and agreed that action to mitigate these effects "require international participation and must start immediately." It also indicated that developed countries, which are also major emission contributors, along with China and India because of their large coal reserves, should take the lead. It established that by the year 2000, developed countries should take action to return GHG emissions, especially $\mathrm{CO}_{2}$, to their 1990 levels. In the long term, the objective of the convention, expressed in Article 2, is to stabilize the concentrations of these gases "at a level which would prevent dangerous anthropogenic interference with the climate system," to ensure that food production is not threatened and to enable sustainable economic development to proceed. It also stipulated that “... the stabilization is to be achieved within a time-frame sufficient to allow ecosystems to adapt naturally to climate change" (IPCC 1995), a desirable but vague objective.

Five sessions of the Conference of the Parties (COP), to the Climate Convention have taken place so far, in March/April 1995, July 1996 and December 1997. The third session, in Kyoto, Japan, focussed on commitments that participating countries can make to reduce GHGs during the early decades of the next century. The fourth session, held in November 1998 in Buenos Aires, Argentina, adopted a two-year plan of action to reduce the risk of global climate change. COP 5, held in late 1999 in Bonn, Germany, attempted to come to an agreement on regulations regarding how to measure and account for GHG emissions, although final agreement on a treaty is still elusive. This process will end with a UN treaty to be negotiated in late 2000 , which is supposed to cut allowable GHG emissions by "developed" countries between 2008 and 2012 by $5 \%$ from those of the year 1990. The final results will have to satisfy the major industrial countries, where GHG emissions continue to increase, and offer incentives to developing countries to take future action.

\section{Stabilizing Emissions}

The FCCC stated that for developed countries, GHGs emissions should be reduced to their 1990 levels by the year 2000 , a target voluntarily announced by some countries, at least for $\mathrm{CO}_{2}$ emissions, even before the Rio conference. Proposed measures include switching to fuels such as natural gas, which for the same energy production generates $40 \%$ and $30 \%$ less $\mathrm{CO}_{2}$ than coal and oil, respectively. By $1995, \mathrm{CO}_{2}$ energy-related emissions of Organisation for Economic Cooperation and Development (OECD) countries had, however, increased by $4 \%$ (Houghton 1997). Implementation of these energy-saving measures could have especially significant effects in countries with heavy industries (iron and steel), which consume enormous amounts of fossil fuel. Also, by 1995, due to voluntary restraint in OECD countries and the economic collapse of the "Countries with Economies in Transition," like the former Soviet Union, energy-related carbon dioxide emissions were almost constant. This will likely continue.

A $15 \%$ reduction relative to 1990 levels is proposed by 2010 (Houghton 1997). In the next phase of negotiations, more substantial and, possibly, longer-term reductions will be discussed.

\section{Forestry Options}

Forestry has an important role to play in mitigating the effects of climate warming. Changes in forest management are long overdue globally because they can be implemented immediately, with no-risk, and will increase the $\mathrm{CO}_{2}$ sink capacity. However, due to rapid population growth, especially in the last five decades of this century, serious social obstacles are raised in developing countries against the implementation of a "pro forest" policy (Gjerstad and South 1999).

As always, even with rudimentary skills and implements resulting in low productivity, food production has an absolute priority. This has put enormous pressure on forests for opening new areas to satisfy immediate needs, regardless of long-term consequences. For the same reason, the productivity of remaining forests has been diminished by unregulated extractions. Today, the map of deforestation tracks the map of population density. The Earth's $\mathrm{CO}_{2}$ sink capacity has been drastically reduced over the last five decades. This is especially true in the tropics, where large areas of forest, primarily on plains with fertile soils, have been cleared for agriculture. Since soils and other conditions were often ill-suited, this clearance often led to soil degradation. Monitoring deforestation from space has provided a clear image of its amplitude - about $1 \%$ of tropical forest lost per year during the 1980s (Houghton 1997). Deforestation had a significant effect on climate warming because of direct reduction of $\mathrm{CO}_{2}$ sequestration, and increased $\mathrm{CO}_{2}$ emissions from soil (exposure allows more heat to reach the soil surface, increasing decomposition and releasing more $\mathrm{CO}_{2}$ ).

Every hectare in the humid tropics has 200 to 500 tonnes of biomass, which releases between 100 to 250 tonnes of carbon through burning, of which about two thirds turns into carbon dioxide (Houghton 1997). With deforestation of $17 \times 10^{6}$ ha during the $1980 \mathrm{~s}$, about $2 \mathrm{Gt}$ of carbon have entered the atmosphere as carbon dioxide (Houghton 1997).

The accuracy of these numbers is uncertain. However, they tally with the IPCC (1995) estimate of carbon entering the atmosphere as $\mathrm{CO}_{2}$ each year from tropical land-use change (mostly deforestation) of $1.6 \pm 1.0 \mathrm{Gt}$ year per year a significant proportion of the current total emissions of carbon dioxide into the atmosphere from human activities. Thus, arresting deforestation will slow down the increase of GHGs in the atmosphere, as well as help preserve biodiversity and arrest erosion.

At the same time, the globe has large areas that are immediately available for reforestation. Every hectare of actively growing forest sequesters between 2 and 5 tonnes of carbon per year (Brown et al. 1996). If 10 million ha are reforested per year, a feasible task, $400 \times 10^{6}$ hectares of new forest will be created by 2040 . By the time the new forests mature ( 40 to 100 years after planting) 25 to $50 \mathrm{Gt}$ of $\mathrm{CO}_{2}$ will have been sequestered from the atmosphere. This amount of carbon would be equivalent to about $10 \%$ of the emissions from 
fossil fuel burnt in the business-as-usual scenario during the first half of the next century, possibly allowing for a relaxation of the fossil fuels restraint. In addition, the $\mathrm{CO}_{2}$ fertilization effect adds an estimated $10 \%$ to these values (Houghton 1997).

Such a monumental task requires a strong commitment. But is such a tree-planting program feasible and is the land available? The answer is almost certainly yes. New studies have identified land that is not now being used for cropland or settlements, much of which has supported forests in the past, totalling about 3.5 million $\mathrm{km}^{2}$. About 2.2 million $\mathrm{km}^{2}$ of this land at mid and high latitudes is technically suitable, and it is all available (Watson et al. 1996). In tropical regions, of the 22 million $\mathrm{km}^{2}$ deemed suitable, only $6 \%$ or 1.3 million $\mathrm{km}^{2}$ is actually available because of social, economic and cultural constraints. Between 1995 and 2050 a reforestation program on this land would likely sequester 50-70 Gt of carbon. Slowing tropical deforestation could sequester 10-20 Gt more. Cost estimates range from 2 to 8 US dollars per tonne of carbon sequestered. This figure does not include land and transaction costs or the value of local benefits (watershed protection, maintenance of biodiversity, education, tourism, and recreation), which in some circumstances might offset most of the programme's cost. In comparison to a cost of between 50 and 100 US dollars per tonne of carbon for likely damage due to global warming, the reforestation programme appears to be very beneficial (Houghton 1997). The sequestration diminishes once the trees are fully grown. What happens then depends on their use. They may be maintained as protection forests, for controlling erosion or conserving biodiversity, or they may became production forests for providing biofuels or industrial timber. If they are used for fuel, they will add to the atmospheric $\mathrm{CO}_{2}$, but unlike fossil fuels they are renewable .

Renewal should begin without delay after harvest. Avoiding long pauses between generations of forest, especially in clearcut plantations, reduces the rate of soil organic matter decomposition.

\section{Adaptation and Mitigation}

Before discussing the options for adaptation and mitigation, it is perhaps useful to reaffirm the fact that the additional carbon that we now find in the atmosphere originates from fossil fuels. This carbon was previously permanently locked. The only places where this carbon could by stored in the future are, in decreasing order: the soil, biomass and oceans. However, in comparison to the past, when the fossil fuel was in a permanent, underground storage, these three pools represent only a transient storage.

The FCCC recognized that the only way to halt climate warming is by stabilizing GHGs, especially carbon dioxide, in the atmosphere. Forestry has been identified as one tool for stabilizing GHGs. However, any forestry response must be part of an integrated effort that includes source reduction. Through photosynthesis, increased forest cover of the planet could retrieve the excess $\mathrm{CO}_{2}$ in the atmosphere, re-establishing the balance between the sources of $\mathrm{CO}_{2}$ and the sinks that existed before the industrial era. Since extensive research has proven that photosynthesis is more effective in an atmosphere with increased $\mathrm{CO}_{2}$, carbon should be retrieved more effectively than when $\mathrm{CO}_{2}$ was scarce (McLeod and Long 1999).

Many of these proposed measures, based almost exclusively on increased timber production, are only short-term solutions. This is because the same decomposition process, or fire, will affect future timber production, releasing $\mathrm{CO}_{2}$ back to the atmosphere. However, soil is a sink with immense capacity. The litter shed annually by a forest decomposes partially and adds to the humus layer. The organic-mineral complexes that form the humus loosely bind carbon and continue to decompose slowly according to an exponential temperature function. As long as the soil is shaded by forest, its $\mathrm{CO}_{2}$ balance is positive. When the soil is exposed, such as in a clearcut, it heats up, decomposition is activated and the $\mathrm{CO}_{2}$ balance switches to negative. Therefore, to use soil as an effective $\mathrm{CO}_{2}$ sink, it must be kept shaded as much as possible.

In dealing with climate change, separate strategies should be devised for adaptation of existing forest ecosystems to future, changed conditions, keeping them productive and in a risk-free state until the end of their rotation, and the mitigation of climate change effects, through restoration of forest productivity and cover. This distinction is necessary because adaptation measures are going to be applied and will be useful only during the present rotation of existing stands, while mitigation measures aim to recover forest cover and productivity, including the use of new, more productive species. Mitigation measures will require long-term, concerted action, namely: (i) reducing GHG emissions, (ii) maintaining existing GHG sinks, and (iii) expanding sinks.

Before examining some realistic options for mitigation and adaptation one has to bear in mind that, given the magnitude of the Earth's atmosphere, there is a long time lag between intervention and remedy (Bolin et al. 1986), which makes close monitoring (atmosphere, soil, water, growth) even more important in the future. While these interventions in the current situation have to be driven by sound science, we have to devise solutions that will not hinder the economy.

Despite the complexity of the challenge, the opportunity exists to implement some necessary changes in forest management and even to profit, at least for the next two to three centuries, from effects such as $\mathrm{CO}_{2}$ fertilization and growing season expansion, which could increase photosynthesis and forest productivity through sequestration of more carbon.

The options for forestry outlined below fall mostly in the "no regrets" category - things that we should be doing anyway. Should climate warming turn out to be less serious than most climatologists believe it will, then there should be no regrets that these measures were implemented. In Canada, and especially in Ontario, these measures will require significant investments. However, significant benefits will be gained as new forests enter a young-mature stage.

A. The suggested adaptation measures examine possibilities to modify existing natural ecosystems and plantations to reduce the potential risks of climate change.

A.1. Reducing the vulnerability of forests to ecological effects of climate warming, especially drought, using extensive thinning as soon as commercial material can be obtained. Periodic density reduction every 5 to 10 years throughout the rotation, in both natural stands and plantations, can (i) improve the soil water balance and reduce moisture stress, (ii) increase the growth of residual trees, and (iii) shorten rotations. The effects of a thinning intervention are most important in terms of micro- 
climate (Aussenac et al. 1984) and soil water regime (Whitehead et al. 1984).

A.2. Introducing intensive forest management on a large scale in natural forests, to increase forest productivity and preserve biodiversity. Stimulation of productivity of existing forests on a large-scale through better matching species to sites, reducing regeneration delays (including by artificial regeneration of climax species), draining peat lands that could flood in the future as water levels rise, and installing local waste recycling systems to enhance biomass production.

\section{A.3. Expansion of stationary ecological research.}

B. The proposed mitigation measures are based on the need to have all lands allocated to forestry occupied by active $\mathrm{CO}_{2}$ retrievers. Although the "area under forest" seems quite large, much of it is not actually occupied by trees, is poorly regenerated, or is covered by low-productivity species:

\section{B.1. Reforesting immediately after harvest (less than three years).}

B.2. Restoring forest cover on bare areas that can sustain (and have sustained) forest production within 10 years, thus reestablishing the $\mathrm{CO}_{2}$ sequestration capacity as well as stopping erosion where it is a problem.

B.3. Gradually shifting species. According to current climate change theory, there is pressure for a northward shift of species ranges (Houghton 1997) that will proceed with differing rhythms for various species (Peter 1990). Considering the delay before this measure will be effective and the atmosphere will respond through a detectable reduction of $\mathrm{CO}_{2}$ concentration, it is rational to establish new forests with species shifted 300 to $600 \mathrm{~km}$ north of the limit of their current natural ranges. Such stands of trees may initially appear to be established in an environment that is too cold for them. However, because the warming process will continue for at least 50 to 100 years in spite of vigorous counteraction, these stands will find themselves in optimal climatic conditions close to the youngmature stage, when they will have the highest sequestration ability or the highest productivity.

B.4. Replacing drought-sensitive species on sites where, potentially, the hydrology will worsen, with more resilient, deeply rooted species. For example, in Canada and the northern US, red pine, which is shallow-rooted, could be replaced with stands of white and red oak or European larch, (both deeply rooted), and American beech could be re-introduced, first on the most drought-sensitive sites (sandy, permeable).

B.5. Establishing plantations of productive species (including mono-specific, industrial plantations), to be managed on the basis of economic principles, to satisfy both the requirements of traditional timber-related industries and the $\mathrm{CO}_{2}$ retrieval function.

B.6. Intensifying forest fire prevention activity, to reduce the release of $\mathrm{CO}_{2}$ into the atmosphere, maintain forest cover on soils and maintain $\mathrm{CO}_{2}$ sinks.
B.7. Developing an integrated surveillance system for forest health and productivity, that monitors the biotic vectors and natural elements, as well as the tree responses.

Regardless of which of the groups they fall into, all strategies must be ecologically sustainable over time, technologically simple, capable of addressing the direct and indirect causes of forest loss by providing economically viable solutions, preferably with low start-up costs, socially integrative, building on local needs and traditions, and relatively adaptable to changing economic and ecological conditions. However, before any strategies are adopted on a wide scale, their relative benefits must be determined. Thus, true net GHGs balance analyses will be necessary, incorporating consideration of all fluxes of multiple gases associated with all phases of growth, harvest, and final disposition of biomass and carbon.

\section{Discussion}

This paper has attempted to present the complex process of climate warming, along with its consequences for Canadian forests. Wherever possible, the probability and pace of change have been predicted, using long-term records of temperature and precipitation from two sites in Ontario. The slope of the temperature line (Figs. 1 and 2 ) is especially significant because it shows the rhythm of the shift of growing conditions.

This analysis provides an understanding of the dynamic character of global warming. As it progresses on a slightly ascending path, it nevertheless maintains its variability. It argues for the opinion that destabilisation of the atmospheric system has to be avoided at any price and that the atmosphere has to be returned, as soon as possible, to the balanced condition existent before the industrial revolution.

The role of adaptation measures is transitional, serving only existing forests. Based especially on density reduction interventions, their role is mainly to avoid the worsening of moisture stress when - because of the climate's variability - a stand of trees will face a longer-than-normal drought. The same stress may occur when, due to age, stand stocking will increase. To a great extent, the suggested measures are based on the results of soil moisture monitoring in a mature red pine thinning experiment (Papadopol unpublished data), which clearly documents that every reduction of the stand basal area is followed by a reduction of the soil water consumption, thus leaving more water available to the residual trees. Hypothesizing that in the future, as a result of increasing climate variability, the stands of trees might be confronted with prolonged drought episodes, which will exacerbate the moisture stress, we attempted to find a way to decrease this stress. The well-tested method of periodic thinning remains the most effective intervention to avoid this risk. More research is needed to fine-tune the interventions to local conditions (species, age, periodicity, intensity, etc.). In real life, economics require that interventions provide some revenue, or at least pay for themselves. With good vegetation control, planting density can be reduced, thus reducing the part of the investment for which the compound interest is paid longest, while obtaining rapid development of the trees planted. Thus, the first intervention can be delayed beyond the age when the first commercial products can be obtained.

Mitigating the effects of climate warming is a much longerterm process. Essentially, it has to deal with the carbon 
released through burning fossil fuels, which can never again be permanently locked underground, and which will be slowly passed along through transitional storage forms. The atmosphere has considerable inertia, thus even a vigorous campaign of forest restoration will not produce tangible results before the end of the $21^{\text {st }}$ century. That is why continuous, sustained action is required as soon as possible.

The predictions used in this paper are based on limited data and do not sufficiently reflect regional differences. However, the long-term trends quantified in Fig. 1 and Fig. 2 are clear, consistent with each other, and have allowed us to sketch further evolutions that are consistent with the results of the GCMs given in the literature (Houghton 1997, Bolin et al. 1986). For instance, analysis of natural forest response assumes that species distributions are currently in equilibrium with current climate variables (Watson et al. 1996). However, existing plantations in Ontario may already be suffering the influence of climate warming and probably would grow better and produce more biomass (especially jack pine and red pine) if their water availability was more consistent (Papadopol 1996). In the case of natural forests the climatic shift will likely result in natural regeneration being successful only in the northern half of their current ranges. More research is needed to determine new southern limits, based on expected changes in climate, at least until the end of the next rotation. In principle, plantation silviculture will be our best bet to maintain the current ranges of species south of this limit.

Predictions based on mean annual temperature and rainfall should be interpreted in the context of generally increased climatic variability and treated with caution when the seasonality of these components and extreme values are not considered. Changes due to such factors as disease and insect attack, nutrition, weed competition, and wind damage on forests have not been included since they require detailed, regional analyses. In addition, species and genotypes could vary in their rate of acclimation (for example, relating to productivity and migration) linked to climate warming.

For the remaining natural forests, management priorities are now oriented towards conservation and watershed protection. Although the impacts of a changing climate on natural forests will be less direct than those on agriculture and plantation forestry, management intervention to protect and maintain current values may be necessary. Such intervention must be preceded by development of clear objectives. For example, at the stand level, the changes occurring in forest composition must be recognized as an inevitable, though short-term, response to a changing environment.

Choices will be more difficult at the species level. Decisions will have to be made about whether to move species due to poor population status or low dispersal capability. The desire to conserve particular species must be balanced against the impacts of artificial establishment on the composition of the surrounding communities. Given the relatively long life span of most natural forest trees, intervention will probably not be needed for at least several decades, unless mortality is accelerated by extreme climatic events.

The relationships among climate, productivity and wood quality of the plantation forest has been investigated. Jackson and Gifford (1974) collected data on periodic volume increment for radiata pine at 132 sites from the range of climates in New Zealand and showed that - after age effects had been removed
$-66 \%$ of the variability could be accounted for by mean annual precipitation, seasonal rainfall distribution, seasonal departures of ambient temperatures from postulated optima, and other site factors such as effective soil depth and nitrogen and phosphorus availability. Hunter and Gibson (1984) sampled 290 plots of Pinus radiata Don. across New Zealand and used principal components analysis to account for differences in site index (mean top height of trees in a stand at 20 years). The site index was found to increase with increasing rainfall and to decrease with the departure from an optimum mean temperature. These approaches need to be analysed further to predict the effects of future climate scenarios on tree growth and wood quality. Comprehensive mensurational data sets will be necessary. Such research is needed to quantify the increased pressure with which ecosystems are pushed to move, concomitantly with the increasing departure from the temperature optima.

A special mention has to be made of the use of genetically improved planting stock. This material has most likely originated from a certain narrow area, with precise characteristics. The developing climate shift complicates the decision about where to plant the genetically improved trees, making the traditional assumptions - stable climate, planting in the region where seeds were collected - inadequate. A better assumption is that they will grow best in areas ecologically similar to their place of origin. However, given the rate of climate warming and the objective to capture the most $\mathrm{CO}_{2}$ in the least time, planting in anticipation of the shift to ensure that the plantation is growing in optimal climatic conditions during early maturity to maturity, when the biomass productivity is highest, will promote maximum productivity and sequestration. This way we might be matching the growth decline of a certain plantation with the end of its rotation. Finally, this assumption should be validated through research aimed at determining the physiological response of species and genotypes to increasing temperature and carbon dioxide concentration, a type of research that can best be done in growth chambers.

Since the threat of ecological change confronts the forestry sector in all regions of the globe, internationally coordinated action is needed in several directions: (a) reduction of fossil fuels burning, (b) reforestation of bare areas that can grow forests, (c) promotion of a "pro carbon" policy, and (d) continuous monitoring of the atmosphere to detect the effect of these measures.

\section{Conclusions}

At the dawn of the third millennium, the greenhouse effect is widely, if not universally, accepted by the international scientific community, and practical action to reverse this effect appears imminent. However, because GCMs have only limited capabilities for modelling the complex interactions among land, ocean and atmosphere, some debate still exists about how fast the climate is warming. It is not clear whether, when and at what $\mathrm{CO}_{2}$ level warming will stabilize, or whether the current, possibly exponential, trend will continue. Also unclear is what mechanism will lead to $\mathrm{CO}_{2}$ stabilization, in the absence of forestry-influenced positive carbon balances.

Most research effort into the impacts and solutions of climate warming has taken place in North America, Europe and Australia. Investigations in Asia are only now beginning and are mainly at the stage of inventorying sources and the magnitude of emissions. Based on evidence, it is clear that human- 
ity must interpret wisely the climatic signal and act promptly to restore the $\mathrm{CO}_{2}$ balance of the Earth, thus avoiding great ecological disruption. Due to its extensive forests and wealth of biological knowledge, Canada can play a major role and set a positive example early in the game. At the same time, it appears that efforts to stabilize and then reverse this global phenomenon also have sizable benefits that should not be neglected. Therefore, preventing its aggravation and mitigating the effects of climate change should be viewed as an investment in the environment, rather than just a survival strategy.

Much more research is needed to improve the certainty of these estimates. To make more detailed predictions about natural forest communities, information will be needed on not only the current relationships between vegetation and climate, but also on the physiological response of plant species to changing climatic and carbon dioxide regimes and the dynamic processes by which adjustment to new climatic regimes occurs.

In this context, monitoring of long-term, permanent sample plots must be continued and expanded to include not only periodic measurements of tree dimensions but also determinations of increment dynamics as related to climatic and soil variables. Such new data will allow increment predictions even for sites on which forests have not yet been established. Such predictions will be useful to assess future growth and $\mathrm{CO}_{2}$ sequestration potential of new areas, when humanity will seriously consider reforestation of all lands available for forestry.

While climate change now appears unavoidable, through concerted efforts it could be maintained within limits that will not affect life's existence until corrective action can restore the situation to pre-industrial revolution levels. Given the atmosphere's inertia, it is obvious that the mitigative actions, especially, will have to be internationally coordinated, longterm and costly.

Finally, field application of the proposed adaptation and mitigation strategies will have to be innovative and preserve a degree of local flexibility.

\section{Acknowledgements}

The author is indebted to the Atmospheric Environment Service of Environment Canada for supplying long-term weather files. He is also grateful for the editorial assistance provided by Lisa Buse, Brian Haddon, and Abigail Obenchain.

\section{References}

Adger, W.N. and K. Brown. 1994. Land Use and the Causes of Global Warming. John Wiley and Sons, Chichester, UK. 271 p.

Andrasko, K. 1990. Global warming and forests: an overview of current knowledge. Unasylva 41: 3-11.

Aussenac, G., A. Granier and R. Naud. 1984. Éclaircie systématique dans un jeune peuplement de douglas-fir. Modifications micro climatiques et influences sur la croissance. Revue Forestière Française 34: 279-288.

Bolin, B., B.R. Doos, J. Jager and R.A. Warrick (eds.). 1986. The Greenhouse Effect, Climate Change and Ecosystems, SCOPE 29. John Wiley and Sons, New York. 541 p.

Boden, T.A., D.P. Kaiser, R.J. Sepanski and F.W. Stoss (eds.). 1994. Trends '93: A Compendium of Data on Global Change. Carbon Dioxide Information Analysis Center. Oak Ridge National Laboratory. Oak Ridge, Tenn., USA. Publication No. ORNL/CDIAC-65. 984 p.

Brown, L. (ed.) 1988. State of The World 1988. Norton, New York.

Brown, S. 1996. Present and potential roles of forests in the global change debate. Unasylva 47: 3-10.

Dixon, R.K., S. Brown, R. A. Houghton, A.M. Solomon. 1994. Carbon Pools and Flux of Global Forest Ecosystems. Science 263 (14 January): 185-190.

Ehleringer, J. and O. Bjorkman. 1977. Quantum yields for $\mathrm{CO}_{2}$ uptake in $\mathrm{C} 3$ and $\mathrm{C} 4$ plants: dependence on temperature, $\mathrm{CO}_{2}$ and $\mathrm{O}_{2}$ concentrations. Plant Physiol., 59: 86-90.

Gjerstad, D.H. and D.B. South. 1999. Population growth versus sustainability, Journal of Forestry 97(3): 48.

Hardy, R. and U. Havelka. 1975. Nitrogen fixation research. Food Science 188: 633-643.

Harries, J. E. 1996. The greenhouse Earth: A view from space. Quart. J. R. Met. Soc., 122: 799-818.

Harrington, J. 1987. Climate change: A review of causes. Can. J. Forest Res. 17: 1313-1339.

Hedden, T. 1987. Potential effects of climate change on insect populations. In G. Pearlman (ed.). Greenhouse: Planning for climate change. CSIRO, Sydney, Australia.

Hunter, I.R. and A.R. Gibson. 1984. Predicting Pinus radiata site index from environmental variables. New Zealand Journal of Forestry Science 14: 53-66.

Houghton, J. 1997. Global Warming. The Complete Briefing. Cambridge University Press, Cambridge, UK. 251 p.

Isaksen, I.S.A. 1992. Radiative Forcing of Climate. In T.J. Houghton, B.A. Callander and S.K.Varney (eds.). Climate Change 1992. The Supplementary Report to The IPCC. CUP. pp. 47-67.

Intergovernmental Panel on Climate Change (IPCC). 1995. Second Assessment. IPCC, Geneva, Switzerland.

Jackson, D.S. and H.H. Gifford. 1974. Environmental variables influencing the increment of radiata pine. (1) Periodic volume increment. New Zealand Journal of Forestry Science 4: 3-26.

Karl, T.R., D.R. Easterling, R.W. Knight and P.Y. Hughes. 1994. U.S. national and regional temperature anomalies. In T.A. Boden, D.P. Kaiser, R.J. Sepanski and F. Stoss (eds.). Trends '93: A Compendium of Data on Global Change, Publication No. ORNL/CDIAC65 pp. 686-736. Carbon Dioxide Information Analysis Center. Oak Ridge National Laboratory. Oak Ridge, Tenn., USA.

Karl, T.R., R.W. Knight, D.R. Easterling and R.G. Quayle. 1996. Indices of climate change for the United States. Bull. Amer. Met. Soc. 77: 279-292.

Kellomaki, S., T. Karjalainen and H. Vaisanen. 1997. More timber from boreal forests under changing climate? Forest Ecology and Management 94: 195-208.

Kramer, P. and N. Sionit. 1987. Effects of increasing carbon dioxide concentration on the physiology and growth of forest trees in stands. In W. Shands and J. Hoffman (eds.). The Greenhouse Effect, Climate Change and US Forests. The Conservation Foundation Washington, DC, USA.

La Marche, V.C., D.A. Graybill, H.C. Fritts and M.R. Rose. 1984. Increasing atmospheric carbon dioxide: Tree ring evidence for growth enhancement in natural vegetation. Science 225: 1019-1021. Lee, H., M.C. Barton and P. Jarvis. 1993. Effects of elevated $\mathrm{CO}_{2}$ on mature Sitka spruce. Vegetatio 104/105: 456-457.

Lee, H.S.J., M. Murray, L. Evans, R. Petterson, I. Leith, C. V. N. Barton and P. G. Jarvis. 1993b. Effects of elevated $\mathrm{CO}_{2}$ on Sitka spruce seedlings. Vegetatio 104/105: 458-459.

Leggett, J. 1990. Global Warming. The Greenpeace Report. Oxford University Press, Oxford, New York. 554 p.

Leggett, J., W.J. Pepper and R.J. Stewart. 1992. Emissions Scenarios For The IPCC: An Update. In T.J. Houghton, B.A. Callander and S.K. Varney (eds.). Climate Change 1992. The Supplementary Report to The IPCC, CUP. pp. 69-95.

Mabbutt, S. 1987. Impacts on semi-arid tropical systems. In G Pearlman (ed.). Greenhouse: Planning for climate change. CSIRO, Sydney, Australia.

Main, A. 1987. Climatic change and its impact on nature conservation in Australia. In G. Pearlman (ed.). Greenhouse: Planning for climate 
change. CSIRO, Sydney, Australia.

McLeod, A.R. and S.P. Long. 1999. Free-air carbon dioxide enrichment (FACE) in Global Change Research: A Review. Advances in Ecological Research 28: 1-56.

Mudge, F.B. 1997. The development of the greenhouse theory of global climate change from Victorian times. Weather 52: 13-16.

Papadopol, C.S. 1996. Impacts of climate change on boreal mixedwood forests in Ontario and ways to mitigate them. In C.R. Smith and G.W. Crook'(eds.). Advancing Boreal Mixedwood Management in Ontario: Proceedings of a Workshop, 17-19 October 1995. pp. 101-105. Published jointly by Natural Resources Canada and Ontario Ministry of Natural Resources, Sault Ste. Marie, Ontario.

Peter, R.L. 1990. Effects of global warming on forests. For. Ecol. Manag. 35: 13-33.

Sedjo, R. and A. Solomon. 1989. Climate and forests. Paper for Workshop on Controlling and Adapting to Greenhouse Forcing, held by the Environmental Protection Agency and the National Academy of Sciences 14-15 June, 1988, Washington, D C. In N. Rosenberg et al. (eds.). Greenhouse warming: abatement and adaptation. Resources for the Future, Washington, DC, USA.

Sionit, N., B.R. Strain, H. Hellmers, G.H. Riechers and C.H. Jaeger. 1985. Long term atmospheric $\mathrm{CO}^{2}$ enrichment affects the growth and development of Liquidambar styraciflua and Pinus taeda seedlings. Can. J. For. Res. 15: 468-571.

Solomon A.M., D.C. West and A.J. Solomon. 1981. Simulating the role of climate change and species immigration in forest succession. In D.D. West, H.H. Shugart and D.B. Botkin (eds.). Forest Succession: Concepts and Applications, pp. 154-177. Springer Verlag, New York, USA.
Tinus, R.W. 1972. $\mathrm{CO}_{2}$ enriched atmosphere speeds growth of Ponderosa pine and blue spruce seedlings. Tree Planters Notes 23: $12-15$.

Tolley, L.C. and B.R. Strain. 1985. Effects of $\mathrm{CO}_{2}$ enrichment on growth of Liquidambar styraciflua and Pinus taeda seedlings grown under different irradiance levels. Oecologia 65: 166-172.

Watson, R.T., M.C. Zinyowera and R.H. Moss (eds.). 1996. Impacts, Adaptations and Mitigation of Climate Change. CUP, Washington, DC, USA. 365 p.

Wheaton, E., T. Singh, R. Dempster, K.O. Higginbotham, J.P. Thorpe, G.C. van Kooten and J.S. Taylor. 1987. An Exploration and Assessment of the Implications of Climate Change for the Boreal Forest and Forestry Economics of the Prairie Provinces and Northwest Territories. Phase I in S.R.C. Technical Report No. 211. Saskatchewan Research Council, Saskatoon, Saskatchewan.

Whitehead, D., P.G. Jarvis, and R.H. Waring. 1984. Stomatal conductance, transpiration, and resistance to water uptake in a Pinus sylvestris spacing experiment. Can. J. For. Res. 14: 692-700.

Whitehead, D., J.R. Leathwick and J.F.F. Hobbs. 1992. How will New Zealand's forests respond to climate change? Potential changes in response to increasing temperature. New Zealand Journal of Forest Science 22(1): 39-53.

Wigley, T.C.M. 1993. Balancing the carbon budget: Implications for projections of future carbon dioxide changes. Tellus 45B: 409-425. Yeatman, C.W.1970. $\mathrm{CO}_{2}$ enriched air increased growth of conifer seedlings. The Forestry Chronicle 46: 229-230. 